\title{
An Improved Fuzzy Comprehensive Evaluation for the Quality Evaluation of Enterprise Logistics Service
}

\author{
Mengyang Wu, Zhengwei Huang, Zhengying Cai \\ China Three Gorges University, Yichang, Hubei, 443002, China \\ E-mail: wumengyang1520@163.com
}

Keywords: Analytic hierarchy process; Cloud model; Group decision; Logistics service quality

\begin{abstract}
Since the e-commerce enterprise change from the price-driven to the service-driven, the logistics service quality has become the key factor to enhance the customer's satisfaction. In the quality evaluation of logistics service, there is an apparent subjectivity in the traditional method to determine the weight of index. Here based on an improved analytic hierarchy process, a cloud model is introduced to improve the scale of evaluation matrix and to obtain the weight of the index by the group decision making method. Then a fuzzy comprehensive evaluation system is used in the Tmall and Jingdong companies as example, where the quality of the logistics service is taken for an empirical study. The results show that the overall logistics service quality of Jingdong is some higher than that of Tmall, but both have the potentiality to utilize and improve in the service quality information.
\end{abstract}

\section{Introduction}

With the fragmentation of internet information and the advancement of cloud computing technology, global commerce comes into the age of e-commerce, with more advantages in precision marketing and personalized service for the customers[1]. Now the enterprise e-commerce starts turning from simple price competition to service competition, where the service quality is mainly divided into two parts, namely online service quality and service quality. When the business flow, capital flow and information flow can be fast implemented on the Internet, the quality of logistics service becomes a key factor to enhance customer satisfaction, and improve customer willingness to buy again[2]. Reference [1] established the evaluation system from the aspects of the price, the accuracy of the commodity information, and the accuracy of delivery, and [2] evaluated the logistics service quality from the time, availability, and integrity.

As logistics service quality, many scholars have established various evaluation systems from different aspects. [3] and [4] mainly emphasized the effect of the accurate and timely delivery on the service quality. As logistics, [5] added the quality of information and personnel communication as the evaluation index of logistics service quality, whereas [6] mainly analyzed the operation quality, related quality and cost quality from the view point of seller. Furthermore [7] considered the logistics service quality emphatically from three aspects: system quality, information quality and service quality. [8] aimed at the characteristics of e-commerce, and maked suggestions for the electric business enterprise from the two points of E service quality and E service recovery quality. From the view of logistics and transportation, [9] researched the effect of the time, availability, integrity of goods and return on customer-perceived service quality.

These references above analyzed some factors to influence the logistics service quality, and try to establish an effective evaluation system of logistics service quality. But most of them built the evaluation method and evaluation process by the traditional crisp evaluation method, and was not practical in many uncertain environment. Based on them, this paper improves the evaluation algorithm by fuzzy mathematics to provide a more practical evaluation tool for the logistics service quality. 


\section{Service quality evaluation model}

The most used evaluation method is the analytic hierarchy process. But the judgment matrix in the traditional hierarchy analysis method has great arbitrariness in scaling assignment, and the fuzziness and uncertainty of expert information in constructing the comparison judgment matrix is not fully considered. So the cloud model is introduced here to improve the standard of judgment matrix, obtain the weight of elements by group decision making. In the establishment of evaluation system, an improved fuzzy AHP method is put forward for fuzzy comprehensive evaluation of logistics service quality. The basic scheme of improved evaluation model is shown in figure 1 .

\begin{tabular}{|c|}
$\begin{array}{c}\text { Selecting the } \\
\text { evaluation index }\end{array} \rightarrow \begin{array}{c}\text { Establishing the } \\
\text { hierarchy } \\
\text { evaluation system }\end{array}$
\end{tabular}$\rightarrow \begin{gathered}\text { Computing the } \\
\text { cloud index weight }\end{gathered} \rightarrow \begin{gathered}\text { Establishing the } \\
\text { fuzzy comprehensive } \\
\text { evaluation model }\end{gathered} \rightarrow \rightarrow \begin{gathered}\text { Outputing the } \\
\text { results }\end{gathered}$

Figure 1 Service quality evaluation model

From figure 1, there are several steps to make AHP evaluation, including index selection, construction of AHP system and weight calculation of indexes, etc. Here cloud is employed as a non-deterministic model of qualitative and quantitative analysis.

Let $\mathrm{C}$ express the qualitative concept, $\mathrm{U}$ express in the quantitative theory of $\mathrm{C}$ with the exact value. Assuming that the parameter $x \in U$ is a random occurrence on the qualitative concept $\mathrm{C}$, where the $\mathrm{X}$ for $\mathrm{C}$ is $\mu(x) \in[0,1]$. If there is a stable tendency of random number, then there is

$\mu: U \rightarrow[0,1], x \in U \in u(x)$

$\mathrm{X}$ in the distribution field $\mathrm{U}$ is called cloud, denoted as $\mathrm{C}(\mathrm{x})$, each $(x, \mu(x))$ is called a cloud. The method to describe the elements of cloud is determined by the factors of evaluation objects $A=\left\{A_{1}, A_{2}, \ldots, A_{n}\right\}$.

Apparently the first level indicators of the main factors should be determined for the evaluation, and then the impact of low-level indicators can be determined by the objectives and factors who affect this level. The definition of decision matrix is scaled as [1,9], and the model is represented by several cloud models, respectively.

$$
A_{0}\left(E x_{0}, E n_{0}, H e_{0}\right), A_{1}\left(E x_{1}, E n_{1}, H e_{1}\right), \ldots, A_{8}\left(E x_{8}, E n_{8}, H e_{8}\right) ;
$$

where the domain is [1,9], the expectation $E x_{0} 、 E x_{1}, \ldots E x_{8}$ are 1,2,.., 9 respectively. Using the golden section method, entropy and entropy can be obtained as

$$
\begin{aligned}
& E n_{0}=E n_{2}=E n_{4}=E n_{6}=E n_{8}=0.382 \cdot\left(\chi_{\text {max }}-\chi_{\text {min }}\right) \alpha / 6=0.437 \\
& E n_{1}=E n_{3}=E n_{5}=E n_{7}=E n_{0} / 0.618=0.707
\end{aligned}
$$

Then the hyper entropy of each cloud model is:

$$
\begin{aligned}
& H e_{0}=H e_{2}=H e_{4}=H e_{6}=H e_{8}=0.382 \cdot\left(\chi_{\max }-\chi_{\text {min }}\right) \beta / 36=0.073 \\
& H e_{1}=H e_{3}=H e_{5}=H e_{7}=H e_{0} / 0.618=0.118
\end{aligned}
$$

So we can get the importance of the matrix in the proposed model as $(1,0.437,0.073)$, $(2,0.707,0.118),(3,0.437,0.073),(4,0.707,0.118),(5,0.437,0.073),(6,0.707,0.118),(7,0.437,0.073)$, $(8,0.707,0.118)$, and $(9,0.437,0.073)$.

\section{Fuzzy Analytic Hierarchy Process}

After comparing the importance of every two elements by cloud model, the importance of the two elements of experts group can be further judged. A method to generate a floating cloud is used to gather the expert's prediction.

In the domain of $U$ there are two adjacent-based cloud, namely $A_{1}\left(E x_{1}, E n_{1}, H e_{1}\right)$, and $A_{2}\left(E x_{2}, E n_{2}, H e_{2}\right)$. To generate a single floating cloud between them, the floating cloud donates the blank linguistic value of them by qualitative concept, and the influence of floating cloud by other 
clouds will be decreased with the increase of their distances. If the number of floating clouds is $A(E x, E n, H e)$, then we can get

$$
\begin{aligned}
& E x=\beta_{1} E x_{1}+\beta_{2} E x_{2} \\
& E n=\frac{E n_{1}\left(E x_{2}-E x\right)+E n_{2}\left(E x-E x_{1}\right)}{E x_{2}-E x_{1}} \\
& H e=\frac{H e_{1}\left(E x_{2}-E x\right)+H e_{2}\left(E x-E x_{1}\right)}{E x_{2}-E x_{1}}
\end{aligned}
$$

where $\beta_{i}(i=1,2)$ is the adjustment coefficient, and $\beta_{1}+\beta_{2}=1$.

According to the group decision-making method, the importance of judgment matrix can be described by two stages of cloud model indexes with respect to the first level indicator, and can be obtained as follows.

$$
\left\{\begin{array}{llll}
a_{11} & a_{12} & \cdots & a_{n 1} \\
a_{21} & \cdots & & \cdots \\
\cdots & & \cdots & \cdots \\
a_{n 1} & & \cdots & a_{n n}
\end{array}\right\}=\left[\begin{array}{ccc}
A_{11}\left(E x_{11}, E n_{11}, H e_{11}\right) & \cdots A_{1 n}\left(E x_{1 n}, E n_{1 n}, H e_{1 n}\right) \\
A_{21}\left(E x_{21}, E n_{21}, H e_{21}\right) & \cdots & \cdots \\
\cdots & & \cdots \\
A_{n 1}\left(E x_{n 1}, E n_{n 1}, H e_{n 1}\right) & A_{n n}\left(E x_{n n}, E n_{1 n}, H e_{n n}\right)
\end{array}\right]
$$

By root mean square method, the relative weights or the importance vector $W_{i}^{0}\left(E x_{i}^{0}, E n_{i}^{0}, H e_{i}^{0}\right)$ of the expectation can be calculated with considered fuzziness and randomness.

$$
\begin{gathered}
E x_{i}^{0}=\frac{E x_{i}}{\sum E x_{i}}=\frac{\left(\prod_{j=1}^{n} E x_{i j}\right)^{\frac{1}{n}}}{\sum_{i=1}^{n}\left(\prod_{j=1}^{n} E x_{i j}\right)^{\frac{1}{n}}} \\
E n_{i}^{0}=\frac{E n_{i}}{\sum E n_{i}}=\frac{\left(\prod_{j=1}^{n} E x_{i j} \sqrt{\left.\sum_{j=1}^{n}\left(\frac{E n_{i j}}{E x_{i j}}\right)^{2}\right)^{\frac{1}{n}}}\right.}{\sum_{i=1}^{n}\left(\left(\prod_{j=1}^{n} E x_{i j}\right) \sqrt{\sum_{j=1}^{n}\left(\frac{E n_{i j}}{E x_{i j}}\right)^{2}}\right)^{\frac{1}{n}}} \\
H e_{i}^{0}=\frac{H e_{i}}{\sum H e_{i}}=\frac{\left(\prod_{j=1}^{n} E x_{i j} \sqrt{\left.\sum_{j=1}^{n}\left(\frac{H e_{i j}}{E x_{i j}}\right)^{2}\right)^{\frac{1}{n}}}\right.}{\sum_{i=1}^{n}\left(\left(\prod_{j=1}^{n} E x_{i j}\right) \sqrt{\sum_{j=1}^{n}\left(\frac{H e_{i j}}{E x_{i j}}\right)^{2}}\right)^{\frac{1}{n}}}
\end{gathered}
$$

Compared with the traditional hierarchical analysis method, equation (6) - (8) can be employed to evaluate expectation, entropy and hyper entropy obtained by group decision making respectively, where the fuzzy and random evaluation of language is also carried out to provide greater objectivity.

The judgment basis for the expectation consistency test is if $C R=\frac{C I}{R I}<0.10$, then the judgment matrix consistency is acceptable, otherwise, the judgment matrix for appropriate amendments should be kept on calculating. Among them, CI is called as the consistency index, where $C I=\frac{\lambda_{\max }-n}{n-1}$, and $R I$ is the average random consistency index of the judgment matrix.

The value of the matrix is the order of these matrixes, and the corresponding relation is shown in Table 1. 
Table 1 The value of RI

\begin{tabular}{|c|c|c|c|c|c|c|c|c|c|}
\hline$n$ & 1 & 2 & 3 & 4 & 5 & 6 & 7 & 8 & 9 \\
\hline$R I$ & 0 & 0 & 0.58 & 0.90 & 1.12 & 1.24 & 1.32 & 1.41 & 1.45 \\
\hline
\end{tabular}

The consistency test can get the weight of each index, and then carry out fuzzy comprehensive evaluation of the logistics service quality, whose complete steps are shown in Figure 2.

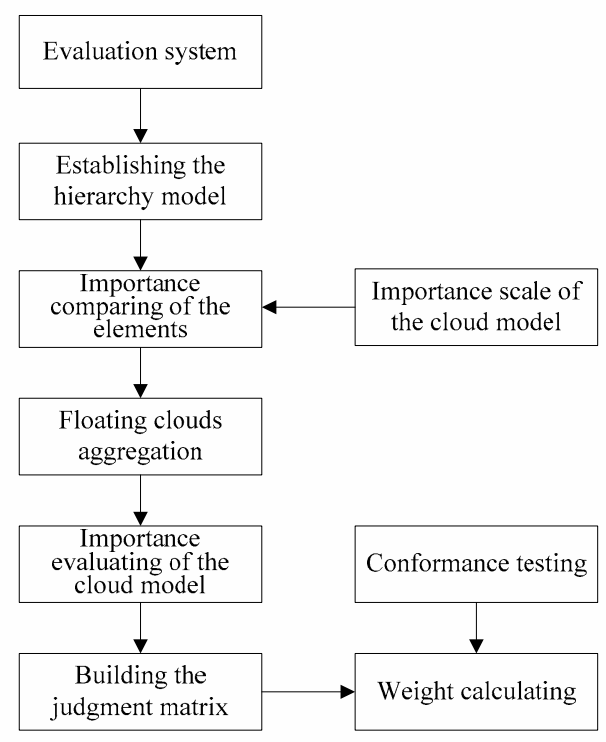

Figure 2 The evaluation processes

(1) To divide the evaluation results into four grades, namely excellent, satisfactory, general, unsatisfactory, and the comment set is $V=\left\{v_{1}, v_{2}, v_{3}, v_{4}\right\}$

(2) To establish the fuzzy evaluation matrix according to the expert's scores, the membership degree matrix $R_{k}$ is obtained by the index $B_{k i}(k=1,2,3,4,5)$ for grade $p$.

(3) To carry out the fuzzy computation on the fuzzy evaluation matrix $R_{k}$ of each index $U_{k i}$ in sub factor layer, and get the subordinate vector $U_{k}$ in main factor layer. Then the fuzzy comprehensive evaluation matrix $R$ is obtained in the comment set $V=\left\{v_{1}, v_{2}, v_{3}, v_{4}\right\}$, and the membership vector of the evaluation set is given by fuzzy calculation.

(4) To numerically evaluate the evaluation results. Supposing $U=\left(u_{1}, u_{2}, \ldots, u_{n}\right), u_{z}=\max _{1 \leq j \leq n}\left\{u_{j}\right\}$, and $\mathrm{N}$ is a number of levels, there are

$$
\begin{aligned}
& \beta=\max _{1 \leq j \leq n}\left\{u_{j}\right\} / \sum_{j=1}^{n} u_{j},\left(\frac{1}{n} \leq \beta \leq 1\right) \\
& \gamma=\sec _{1 \leq j \leq n}\left\{u_{j}\right\} / \sum_{j=1}^{n} u_{j},(0 \leq \gamma \leq 0.5)
\end{aligned}
$$

where $\sec _{1 \leq j \leq n}\left\{u_{j}\right\}$ represents the second major components of $U$. The effective degree of the maximum membership method is $\alpha$, which is defined $\alpha=\frac{n \beta-1}{2 \gamma(n-1)}$, then the effectiveness of the maximum membership principle can be determined according to $\alpha$.

\section{Experiment}

\section{Questionnaire and data collecting.}

The article takes two e-commerce giants, Tmall and Jingdong companies for example, whose logistics service quality of suppliers are analyzed and compared. Tmall is a well-known integrated platform based shopping site in China, and its logistics service is still dependent on the third party logistics. Jingdong Mall is the largest shopping platform of self B2C in China, and its logistics 
model is self-built distribution system integrating the third party logistics enterprises.

Above all, it is to establish the evaluation system for the service quality of e-commerce logistics according to the proposed hierarchical structure model.

To determine the weight of each index, the questionnaires are employed to survey market and collect data. Based on the analytic hierarchy process and cloud model, index weight of service quality can be calculated for the e-commerce logistics. About 500 survey questionnaires are distributed online to volunteers and consumers on the quality of logistics service, and the main object group is the young people around 20-30 years old with rich online shopping experience and good understanding on these quality indexes.

Index weight determination.

Now, according to the equation (2) and (3), it is to describe the importance of the cloud, to get the judgment matrix between different 5 indexes $\{\mathrm{B} 1-\mathrm{B} 5\}$. The A-B judgment matrix is shown in table 2 .

Table 2 A-B judgment matrix

\begin{tabular}{|c|c|c|c|c|c|}
\hline A & B1 & B2 & B3 & B4 & B5 \\
\hline B1 & $(1,0,0)$ & $(0.364,0.042,0.007)$ & $(3,0.338,0.049)$ & $(5.125,0.403,0.058)$ & $(2.25,0.312,0.047)$ \\
\hline B2 & $(2.75,0.317,0.052)$ & $(1,0,0)$ & $(6.75,0.564,0.095)$ & $(3.25,0.339,0.064)$ & $(5.5,0.518,0.086)$ \\
\hline B3 & $(0.333,0.043,0.013)$ & $(0.148,0.017,0.003)$ & $(1,0,0)$ & $(2.125,0.257,0.043)$ & $(6.75,0.682,0.098)$ \\
\hline B4 & $(0.195,0.015,0.002)$ & $(0.308,0.032,0.006)$ & $(0.471,0.062,0.011)$ & $(1,0,0)$ & $(1,0,0)$ \\
\hline B5 & $(0.444,0.056,0.009)$ & $(0.182,0.017,0.003)$ & $(0.148,0.682,0.098)$ & $(1,0,0)$ & $(1,0,0)$ \\
\hline
\end{tabular}

Then the relative weight of $\mathrm{A}$ to $\mathrm{B}$ is given as

$$
W=\left[\begin{array}{c}
(0.477,0.443,0.278) \\
(0.073,0.067,0.083) \\
(0.247,0.236,0.278) \\
(0.062,0.107,0.099) \\
(0.140,0.443,0.460)
\end{array}\right]
$$

Additionally, it is to test the conformance of expectations, and $C I=0.087, R I=1.12$, $C R=C I / R I=0.078<0.10$.Then, the weights of the indicators in first layer and the second layer are calculated in Table 3.

Table 3 Weight table

\begin{tabular}{|c|c|c|c|}
\hline Index in $1^{\text {st }}$ layer & Weight in ${ }^{\text {st }}$ layer & Index in $2^{\text {nd }}$ layer & Weight in $2^{\text {nd }}$ layer \\
\hline \multirow{3}{*}{$\begin{array}{c}\text { Reliability } \\
B_{1}\end{array}$} & \multirow{3}{*}{0.477} & Order Accuracy & 0.099 \\
\hline & & Cargo Integrity & 0.478 \\
\hline & & Delivery Accuracy & 0.423 \\
\hline \multirow{4}{*}{$\begin{array}{c}\text { Response } \\
B_{2}\end{array}$} & \multirow{4}{*}{0.073} & Order Response & 0.278 \\
\hline & & Leading Time & 0.478 \\
\hline & & Return Response Time & 0.116 \\
\hline & & Out Of Capacity & 0.129 \\
\hline \multirow{2}{*}{$\begin{array}{c}\text { Economy } \\
B_{3}\end{array}$} & \multirow{2}{*}{0.248} & Logistics Price & 0.692 \\
\hline & & Return Cost & 0.308 \\
\hline \multirow{3}{*}{$\begin{array}{c}\text { Convenience } \\
B_{4}\end{array}$} & \multirow{3}{*}{0.062} & Deliver Convenience & 0.294 \\
\hline & & Take Delivery & 0.633 \\
\hline & & Return & 0.073 \\
\hline \multirow{3}{*}{$\begin{array}{c}\text { Information } \\
B_{5}\end{array}$} & \multirow{3}{*}{0.14} & Information Sufficiency & 0.245 \\
\hline & & Information Accuracy & 0.657 \\
\hline & & Error Feed-Back & 0.099 \\
\hline
\end{tabular}


So the judgment matrix satisfies the consistency. In the same way, the judgment matrix $B_{k}-C$, the weight of each level index $W_{i}$, and the corresponding grade between every two indexes can be all gotten.

\section{Fuzzy comprehensive evaluation.}

According to the fuzzy comprehensive evaluation process, the membership vector is calculated.

$$
\begin{gathered}
U_{\text {Tmall }}=(0.4092,0,2966,0.1616,0.1328) \\
U_{\text {Jingdong }}=(0.5260,0.2596,0.1347,0.0798)
\end{gathered}
$$

The effective degree can be further calculated,

$$
\begin{gathered}
\alpha_{\text {Tmall }}=0.3577<0.5 \\
\alpha_{\text {Jingdong }}=0.7088>0.5
\end{gathered}
$$

From the evaluation results, the Tmall is less efficient than Jingdong. Then the weighted average method is used to quantify the evaluation results, where the four evaluation levels in the text are 1,2 , 3,4 , and the final results are obtained as follows.

$$
\begin{gathered}
E V_{\text {Tmall }}=\frac{\sum_{j=1}^{n} u_{j}^{k} \cdot j}{\sum_{j=1}^{n} u_{j}^{k}}=1.6455 \\
E V_{\text {Jingdong }}=\frac{\sum_{j=1}^{n} u_{j}^{k} \cdot j}{\sum_{j=1}^{n} u_{j}^{k}}=1.3331
\end{gathered}
$$

The logistics quality evaluation result of Tmall is 1.3331 , and Jingdong Mall is 1.6455 , therefore, it is can be considered that the overall logistics service quality of Jingdong Mall is higher than that of Tmall.

As each level index, the Tmall quantitative evaluation results is $(1.69,1.48,1.61,1.70,1.73)$, and Jingdong Mall fruit is $(1.63,1.45,1.74,1.33,1.46)$. That is to say, Jingdong Mall take advantages over Tmall in service reliability, service response, service facilities and service information of logistics service quality, but its service economy is inferior to that of Tmall. In terms of service information, Tmall and Jingdong Mall both have a potentiality for improve, especially in the error feedback ability of information.

After comparing the logistics service quality of Tmall and Jingdong Mall, several interesting suggestions can be gotten. The results showed that whether it is third-party logistics or not, business enterprise should establish error information collection and feedback mechanism to solve the problems generated by the lacking of information or failed feedback or tracking. It is helpful to improve the convenience of Tmall, such as improving the delivery way of diversity, strengthening the reverse logistics, the return process optimization of goods or service, in order to improve the customer satisfaction and perception.

\section{Conclusions}

Now e-commerce turn from the price driven to the service driven, and customers are also changed from the impulse role to the buy one. These changes put forward higher requirements for the service quality of e-commerce. With the improved AHP, the logistics service quality analysis can be carried out and compared. Only by strengthening the management of information and cooperation, can we guarantee the smooth transmission of information between the enterprises and the logistics suppliers to improve the efficiency and accuracy of logistics management. At the same time, our research simplified the third party logistics and not revealed the relationship between two 
hybrid collaboration quality, which our future will be focused on, as well as the self-supporting logistics mode of logistics service quality.

\section{Acknowledgement}

This work was supported by the National Natural Science Foundation of China (No. 71471102).

\section{References}

[1] Perrault W D, Russ F. Physical Distrbution Service: A Neglected Aspect of Markting Management[J]. MUS Business Topics, 1974, 22(2): 37-45.

[2] Mentzer, T.J, Gomes R, et al. Physical distribution service: A fundamental marketing concept[J]. Journal of the Academy of Marketing Science, 1989, (17): 53-62.

[3] Workgroup N. Performance indicators in logistics[J]. IFS Ltd. and Springer-Verlag, Bedford (UK), 1989.

[4] Cooke P, Morgan K. The associational economy: firms, regions, and innovation[J]. OUP Catalogue, 1999.

[5] Mentzer J T, Flint D J, Kent J L. Developing a logistics service quality scale[J]. Journal of Business, 1999, 20(1): 9-32.

[6] Stank T P, Goldsby T J, Vickery S K, et al. Logistics service performance: estimating its influence on market share[J]. Journal of Business Logistics, 2003, 24(1): 27-55.

[7] Parasuraman A, Zeithaml V A, Malhotra A. ES-QUAL a multiple-item scale for assessing electronic service quality[J]. Journal of service research, 2005, 7(3): 213-233.

[8] Xing Y, Grant D B. Developing a framework for measuring physical distribution service quality of multi-channel and "pure player" internet retailers[J]. International Journal of Retail \& Distribution Management, 2006, 34(4/5): 278-289.

[9] Wang H, Feng Y. On multiple attribute group decision making with linguistic assessment information based on cloud model[J]. Control and Decision, 2005, 20(6): 679. 